\title{
Impact of cumulative area-based adverse socioeconomic environment on body mass index and overweight
}

\author{
E Regidor, J L Gutiérrez-Fisac, E Ronda, M E Calle, D Martínez and V \\ Domínguez \\ J. Epidemiol. Community Health 2008;62;231-238 \\ doi:10.1136/jech.2006.059360
}

Updated information and services can be found at:

http://jech.bmj.com/cgi/content/full/62/3/231

\section{References}

Rapid responses

Email alerting service

\section{These include:}

This article cites 37 articles, 16 of which can be accessed free at: http://jech.bmj.com/cgi/content/full/62/3/231\#BIBL

You can respond to this article at:

http://jech.bmj.com/cgi/eletter-submit/62/3/231

Receive free email alerts when new articles cite this article - sign up in the box at the top right corner of the article

Notes

To order reprints of this article go to:

http://journals.bmj.com/cgi/reprintform

To subscribe to Journal of Epidemiology and Community Health go to:

http://journals.bmj.com/subscriptions/ 


\title{
Impact of cumulative area-based adverse socioeconomic environment on body mass index and overweight
}

\author{
E Regidor, ${ }^{1} \mathrm{~J}$ L Gutiérrez-Fisac, ${ }^{2}$ E Ronda, ${ }^{3}$ M E Calle, ${ }^{1}$ D Martínez, ${ }^{1}$ V Domínguez ${ }^{1}$
}

${ }^{1}$ Department of Preventive Medicine and Public Health, Universidad Complutense de Madrid, Madrid, Spain;

${ }^{2}$ Department of Preventive Medicine and Public Health, Universidad Autónoma de

Madrid, Madrid, Spain;

${ }^{3}$ Department of Public Health,

Universidad de Alicante,

Alicante, Spain

Correspondence to:

E Regidor, Department of

Preventive Medicine and Public

Health, Faculty of Medicine,

Universidad Complutense de

Madrid, Ciudad Universitaria,

28040 Madrid, Spain:

enriqueregidor@hotmail.com

Accepted 8 May 2007

\author{
ABSTRACT \\ Objective: Although the relationship between area \\ socioeconomic environment and obesity is known, \\ previous research has measured area socioeconomic \\ environment at only one point in time. This study \\ evaluates the relationship of cumulative area-based \\ adverse socioeconomic environment with body mass \\ index (BMI) and overweight. \\ Design: Cross-sectional study. \\ Setting: Spain. \\ Participants: 17917 subjects in 2001. \\ Main outcome measure: Information from 1980, 1990
} and 2000 was used for the percentage of the population with low educational achievement, gross domestic product per capita (GDPp), and Gini coefficient to estimate BMI and prevalence of overweight by the number of times each province had an adverse exposure to each of these measures of socioeconomic environment.

Results: After adjusting for individual variables and sports facilities in the area, the difference in BMl in residents of provinces with the highest percentage of population with low educational achievement in 1980, 1990 and 2000, compared with residents of provinces with no history of adverse socioeconomic environment based on this indicator, was $0.61 \mathrm{~kg} / \mathrm{m}^{2}$, whereas the prevalence of overweight was 1.46 times higher. Similar results were obtained for residents of provinces with cumulative low GDPpc versus residents of provinces that had never had low GDPpc. Neither BMI nor overweight were associated with cumulative income inequality based on the Gini coefficient.

Conclusion: Cumulative adverse socioeconomic environment based on indicators of educational level or wealth, but not of income inequality, is positively associated with $\mathrm{BMI}$ and overweight. This association is not explained by individual characteristics or by the availability of sports facilities.

The relationship between socioeconomic environment and obesity is well established. Mean body mass index (BMI) and prevalence of overweight are higher in areas with greater material deprivation and in those with larger income inequality. ${ }^{1-6}$

It has been proposed that health behaviours such as dietary patterns, physical inactivity, alcohol intake and smoking play an important mediating role. ${ }^{14}$ Differences in area facilities, such as the availability and price of healthy food and the absence of sports and recreational facilities, may give rise to area differences in dietary intake and physical inactivity. ${ }^{7-11}$ Poorer areas and those with higher income inequality may provide fewer opportunity structures for health-promoting activities than more affluent areas and those with lower income inequality. ${ }^{135}$ The possible mediating role of psychosocial factors has also been suggested. ${ }^{3-6}$ The chronic stress generated by a person's perception of how his income ranks in comparison with others could affect obesity directly or indirectly through behaviours such as smoking, drinking, and overeating. ${ }^{12} 13$

All previous investigations have measured indicators of area-based socioeconomic environment at a single point in time. Any effect of socioeconomic environment on BMI and overweight is, however, highly unlikely to be instantaneous. The availability of facilities and the level of stress in an area probably reflect the socioeconomic environment over time and not so much the socioeconomic environment at that particular moment. The failure to consider cumulative exposure to the socioeconomic environment of the area of residence may represent a limitation when determining how socioeconomic context is related to BMI and overweight.

In this investigation we used information on three indices of socioeconomic environment, educational level, wealth and income inequality, over the last two decades of the 20th century to evaluate the relationship of cumulative area-based adverse socioeconomic environment with BMI and overweight in the Spanish population in 2001.

\section{METHODS}

\section{Study population}

Study subjects were taken from the 2001 National Health Survey. Individuals were selected using a multistage procedure in each of the 50 provinces: first, towns were chosen by random selection proportional to the size of the population, and then census areas were chosen by simple random selection. The median number of residents in the Spanish provinces was 535000 inhabitants, with an interquartile range of 345000-900 000. The non-response rate was $15 \%$. The study was restricted to the population aged 16-74 years. Older individuals were not included because the health survey excluded institutionalised persons from the sample, and the probability of being institutionalised is relatively high in those over 74 years.

\section{Individual-level variables}

Information on weight and height was collected by asking: "About how much do you weigh without your shoes or clothes on? (in kg)" and "About how 
Table 1 Sample size, characteristics of study subjects, and mean number of sports facilities per 1000 population, by indices of cumulative area-based adverse socioeconomic environment

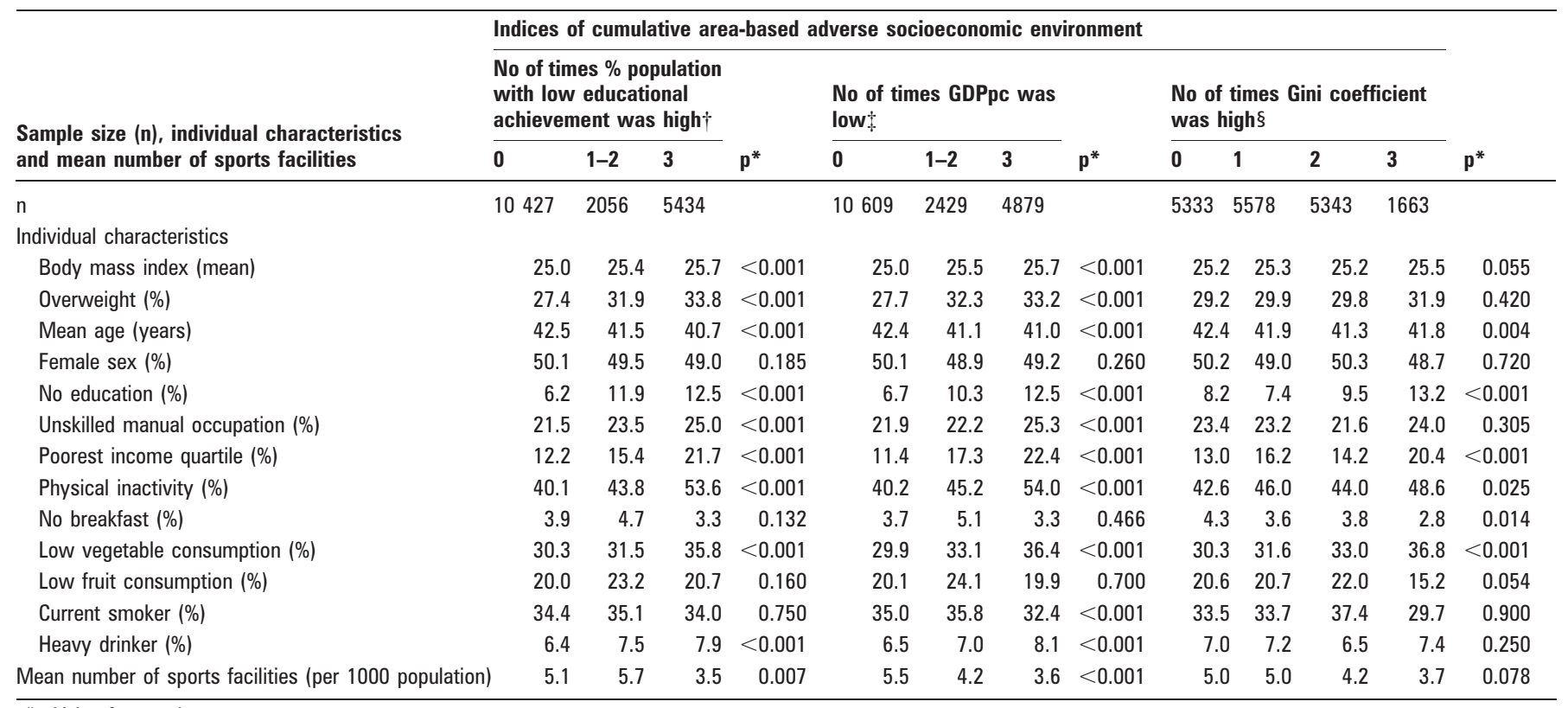

*p Value for trend.

† Number of times percentage of population with low educational achievement was above the 60th percentile in 1980, 1990, and 2000.

\$Number of times gross domestic product per capita was below the 40th percentile in 1980, 1990, and 2000.

§Number of times Gini coefficient was above the 60th percentile in 1980, 1990, and 1999.

tall are you are without your shoes on? (in $\mathrm{cm}$ )". The nonresponse rate to weight and/or height was $10.2 \%$. BMI was calculated as weight in kilograms divided by height in square metres. Overweight was defined as a BMI of 27 or greater, because the risk of mortality increases after this cut-off point. ${ }^{14}$

Monthly household income, social class, and highest level of education completed by the person interviewed were the measures of socioeconomic position. The response categories for the question on income consisted of six income ranges. Income was assigned to each person by transforming this variable into a quantitative variable using the mid-point of each interval and dividing by the square root of the number of individuals in the household, using the equivalence scale of the Luxembourg Income Study. ${ }^{15}$ The quartiles of the distribution of household equivalent income were then estimated, and each respondent was included in one of these quartiles. The $20 \%$ of subjects with missing information on income were included in an additional category. Most of these individuals probably had high income because $70 \%$ of them had 12 or more years of education. Social class was assigned on the basis of the occupation of the head of household. Occupation was coded in accordance with the National Classification of Occupations and subjects were assigned to one of the following categories: professionals, managers and intermediate professions (I), self-employed workers and workers in the service industry (II), skilled manual workers (III) and unskilled manual workers (IV). Finally, subjects were assigned to one of four categories based on the highest educational level achieved: no education (fewer than five years), primary level (five years), low secondary level (nine years), and high secondary/third level (12 years or more).

Subjects were asked about the type of physical exercise done in their free time. The response categories were: (1) no exercise; (2) occasional physical activity (walking, riding a bicycle, gardening, light exercise, recreational activities requiring moderate effort, etc); (3) regular physical activity several times a month (tennis, gym, running, swimming, cycling, team games, etc); and (4) vigorous exercise several times a week.

As skipping breakfast has been associated with an increased prevalence of obesity, ${ }^{16}$ participants were grouped into three categories depending on the type of breakfast: no breakfast; something liquid (coffee, tea, milk, juices) with or without toast or sweet rolls; and a more substantial breakfast (eggs, ham, cheese, etc, and something liquid). Participants were also asked about their weekly intake of different foods. The consumption of fruits and vegetables less than three days a week was considered to be low. Smoking was categorised as current smoker if the person was a regular or daily smoker, and nonsmoker for all others. Alcohol intake was measured using a quantity-frequency index. Heavy drinkers were considered to be those with a daily consumption of more than $50 \mathrm{ml}$ (men) or $30 \mathrm{ml}$ (women) of absolute alcohol.

\section{Area-level variables}

We estimated three indicators of socioeconomic environment in each of the 50 Spanish provinces around 1980, 1990 and 2000: the proportion of the population with low educational achievement (less than primary level) as the indicator of underinvestment in human capital; gross domestic product per capita (GDPpc) as the indicator of wealth, and the Gini coefficient as the indicator of income inequality. On the basis of these indicators we estimated three indices that reflect the cumulative exposure of each province to an adverse economic environment in the last two decades of the 20th century.

For the first index we calculated the proportion of people aged 10 years and older with low educational achievement based on the population censuses of 1981, 1991 and 2001, and then calculated for each province the number of times this percentage was higher than the 60th percentile. We constructed a combined index describing the number of adverse exposures in each province: provinces with no unfavourable exposures were at one end of the index, and those with three unfavourable 
Table 2 Associations between individual characteristics and BMI and overweight

\begin{tabular}{|c|c|c|}
\hline \multirow[b]{2}{*}{ Individual characteristics } & \multirow{2}{*}{$\frac{\text { BMI }}{\text { Difference }(95 \% \mathrm{CI})}$} & \multirow{2}{*}{$\begin{array}{l}\text { Overweight } \\
\text { Odds ratio }(95 \% \text { Cl) }\end{array}$} \\
\hline & & \\
\hline Age $^{*}$ & $0.08(0.07$ to 0.08$)$ & $1.03(1.03$ to 1.04$)$ \\
\hline \multicolumn{3}{|l|}{ Sex } \\
\hline Men & 0.00 & 1.00 \\
\hline Women & $-1.36(-1.47$ to -1.24$)$ & $0.61(0.57$ to 0.66$)$ \\
\hline \multicolumn{3}{|l|}{ Education } \\
\hline High secondary/third level & 0.00 & 1.00 \\
\hline Low secondary level & $0.61(0.47$ to 0.76$)$ & $1.49(1.35$ to 1.64$)$ \\
\hline Primary level & $1.15(0.97$ to 1.33$)$ & 1.89 (1.69 to 2.53$)$ \\
\hline No education & $1.53(1.27$ to 1.79$)$ & $2.17(1.86$ to 2.53$)$ \\
\hline \multicolumn{3}{|l|}{ Social class $\dagger$} \\
\hline 1 & 0.00 & 1.00 \\
\hline II & $-0.05(-0.23$ to 0.13$)$ & $1.08(0.96$ to 1.22$)$ \\
\hline III & $0.34(0.19$ to 0.50$)$ & $1.22(1.10$ to 1.35$)$ \\
\hline IV & 0.26 (0.09 to 0.43$)$ & $1.18(1.06$ to 1.32$)$ \\
\hline \multicolumn{3}{|l|}{ Equivalent household income } \\
\hline Missing & $-0.34(-0.53$ to -0.14$)$ & $0.79(0.69$ to 0.90$)$ \\
\hline$>867.5$ euros & 0.00 & 1.00 \\
\hline $608-867.5$ euros & $0.18(-0.03$ to 0.39$)$ & $1.02(0.88$ to 1.18$)$ \\
\hline $434-607.9$ euros & $0.17(-0.03$ to 0.36$)$ & $1.00(0.88$ to 1.13$)$ \\
\hline$<434$ euros & $-0.13(-0.38$ to 0.12$)$ & $0.86(0.74$ to 1.01$)$ \\
\hline \multicolumn{3}{|l|}{ Physical activity } \\
\hline Vigorous excercise & 0.00 & 1.00 \\
\hline Regular physical activity & $-0.02(-0.29$ to 0.25$)$ & $1.02(0.82$ to 1.27$)$ \\
\hline Occasional physical activity & 0.34 (0.11 to 0.57$)$ & $1.54(1.29$ to 1.85$)$ \\
\hline No exercise & $0.74(0.51$ to 0.97$)$ & 1.96 (1.63 to 2.34$)$ \\
\hline \multicolumn{3}{|l|}{ Breakfast } \\
\hline Substantial breakfast & 0.00 & 1.00 \\
\hline Coffee and/or tea and/or sweet rolls & $-0.03(-0.30$ to 0.23$)$ & $0.91(0.77$ to 1.07$)$ \\
\hline No breakfast & $0.79(0.65$ to 0.94$)$ & $1.48(1.18$ to 1.87$)$ \\
\hline \multicolumn{3}{|l|}{ Vegetable consumption } \\
\hline Three or more times a week & 0.00 & 1.00 \\
\hline Less than 3 times a week & $0.15(0.02$ to 0.27$)$ & $0.94(0.87$ to 1.02$)$ \\
\hline \multicolumn{3}{|l|}{ Fruit consumption } \\
\hline Three or more times a week & 0.00 & 1.00 \\
\hline Less than 3 times a week & $-0.08(-0.23$ to 0.06$)$ & $1.12(1.02$ to 1.23$)$ \\
\hline \multicolumn{3}{|l|}{ Current smoker } \\
\hline No & 0.00 & 1.00 \\
\hline Yes & $-0.51(-0.63$ to -0.39$)$ & $0.77(0.71$ to 0.83$)$ \\
\hline \multicolumn{3}{|l|}{ Heavy drinker } \\
\hline No & 0.00 & 1.00 \\
\hline Yes & $0.23(0.00$ to 0.45$)$ & $1.19(1.04$ to 1.36$)$ \\
\hline
\end{tabular}

BMI, Body mass index.

${ }^{*}$ This is a continuous variable.

$\dagger$ l: professionals, managers and intermediate professions; II: self-employed and workers in service industry; III: skilled manual workers; IV: unskilled manual workers.

exposures were at the other. For the second index we used the information on provincial GDPpc provided by Eurostat for the years 1980, 1990 and $2000,{ }^{17}$ and calculated the number of times that the GDPpc in each province was lower than the 40th percentile. We then constructed a combined index, similar to the one previously described. For the third index we used the Gini coefficient for the years 1980, 1990 (calculated by the Valencian Institute of Economic Research from the Household Budget Surveys of 1980 and 1990) ${ }^{18}$ and 1999 (calculated from the 1999 National Survey on Disabilities), and calculated the number of times the Gini coefficient for each province was higher than the 60th percentile. We then constructed a combined index in a similar way. We chose the 60 th percentile (40th for GDPpc) from the distribution of provincial values because these cut-off points ensured the presence of provinces in all four categories defined for each index. The use of stricter cutoff points would have left the intermediate categories of the combined index without any provinces.

Information on the number of sports facilities in each province was obtained from the 1998 National Census of Sports Installations, which includes all collective sports installations, plus the sports facilities contained in each of them. We estimated the number of sports facilities per 1000 population in each province. Because within-province heterogeneity, in terms of urbanity/rurality or population density, may affect the relationship between the availability of sports facilities and physical inactivity, we used as control variables the percentage of the population living in municipalities with fewer than 20000 inhabitants and the population density per square kilometer in each province. 
Table 3 Difference $(95 \% \mathrm{Cl})$ in $\mathrm{BMI}$ according to cumulative area-based adverse socioeconomic environment indices, province and individual-level variance and intraclass correlation

\begin{tabular}{|c|c|c|c|c|}
\hline Index of socioeconomic environment & Adjusted for age and sex & $\begin{array}{l}\text { Adjusted for age, sex, } \\
\text { and measures of SEP* }\end{array}$ & $\begin{array}{l}\text { Adjusted for age, sex, } \\
\text { measures of SEP, and } \\
\text { health behaviours } \uparrow\end{array}$ & $\begin{array}{l}\text { Adjusted for age, sex, } \\
\text { measures of SEP, health } \\
\text { behaviours:, and sports } \\
\text { facilities }\end{array}$ \\
\hline \multicolumn{5}{|l|}{$\begin{array}{l}\text { No of times \% population with low } \\
\text { educational achievement was high§ }\end{array}$} \\
\hline 0 & 0.00 & 0.00 & 0.00 & 0.00 \\
\hline $1-2$ & $0.54(0.21$ to 0.86$)$ & $0.39(0.12$ to 0.66$)$ & $0.38(0.10$ to 0.67$)$ & $0.41(0.14$ to 0.68$)$ \\
\hline 3 & 0.84 (0.60 to 1.07$)$ & $0.65(0.45$ to 0.85$)$ & $0.63(0.42$ to 0.84$)$ & $0.61(0.40$ to 0.82$)$ \\
\hline $\mathrm{p}$ Value for trend & $<0.001$ & $<0.001$ & $<0.001$ & $<0.001$ \\
\hline Province-level variance (SE) & $0.092(0.032)$ & $0.053(0.022)$ & $0.061(0.024)$ & $0.050(0.023)$ \\
\hline Individual-level variance (SE) & $17.3(0.15)$ & $13.4(0.14)$ & $13.2(0.14)$ & $13.2(0.14)$ \\
\hline ICC & $0.7 \%$ & $0.3 \%$ & $0.5 \%$ & $0.4 \%$ \\
\hline-2 Log likelihood & 95801.8 & 95355.9 & 94462.1 & 94522.8 \\
\hline \multicolumn{5}{|l|}{ No of times GDPpc was low } \\
\hline 0 & 0.00 & 0.00 & 0.00 & 0.00 \\
\hline $1-2$ & $0.59(0.25$ to 0.94$)$ & $0.43(0.15$ to 0.71$)$ & $0.44(0.14$ to 0.73$)$ & $0.44(0.16$ to 0.73$)$ \\
\hline 3 & $0.72(0.45$ to 0.99$)$ & $0.56(0.33$ to 0.78$)$ & $0.53(0.30$ to 0.76$)$ & $0.49(0.24$ to 0.74$)$ \\
\hline $\mathrm{p}$ Value for trend & $<0.001$ & $<0.001$ & $<0.001$ & $<0.001$ \\
\hline Province-level variance (SE) & $0.124(0.040)$ & $0.070(0.028)$ & $0.082(0.031)$ & $0.074(0.029)$ \\
\hline Individual-level variance (SE) & $13.7(0.15)$ & $13.4(0.14)$ & $13.2(0.14)$ & $13.2(0.14)$ \\
\hline ICC & $0.9 \%$ & $0.5 \%$ & $0.6 \%$ & $0.6 \%$ \\
\hline-2 Log likelihood & 95812.0 & 95365.2 & 94471.5 & 94525.7 \\
\hline \multicolumn{5}{|l|}{ No of times Gini coefficient was high ${ }^{* *}$} \\
\hline 0 & 0.00 & 0.00 & 0.00 & 0.00 \\
\hline 1 & $0.32(-0.07$ to 0.71$)$ & $0.22(-0.09$ to 0.54$)$ & $0.20(-0.12$ to 0.51$)$ & $0.24(-0.07$ to 0.54$)$ \\
\hline 2 & $0.34(-0.10$ to 0.78$)$ & $0.27(-0.09$ to 0.62$)$ & $0.31(-0.05$ to 0.66$)$ & $0.28(-0.06$ to 0.63$)$ \\
\hline 3 & $0.41(-0.08$ to 0.90$)$ & $0.32(-0.08$ to 0.72$)$ & $0.30(-0.10$ to 0.71$)$ & $0.24(-0.16$ to 0.64$)$ \\
\hline $\mathrm{p}$ Value for trend & 0.066 & 0.073 & 0.066 & 0.120 \\
\hline Province-level variance (SE) & $0.218(0.062)$ & $0.122(0.041)$ & $0.122(0.042)$ & $0.114(0.039)$ \\
\hline Individual-level variance (SE) & $13.7(0.15)$ & $13.4(0.14)$ & $13.2(0.14)$ & $13.3(0.14)$ \\
\hline ICC & $1.5 \%$ & $0.9 \%$ & $0.9 \%$ & $0.8 \%$ \\
\hline-2 Log likelihood & 95830.3 & 95381.4 & 94483.8 & 94536.2 \\
\hline
\end{tabular}

BMI, Body mass index; GDPpc, gross domestic product per capita; ICC, intraclass correlation coefficient; SE, standard error; SEP, socioeconomic position.

${ }^{*}$ Social class, educational level and income.

†Health behaviours: type of breakfast, consumption of fruits and vegetables, smoking, drinking, and physical activity.

\$Physical activity was not included.

$\S$ Number of times percentage of population with low educational achievement was above the 60th percentile in 1980, 1990 , and 2000.

- Number of times GDPpc was below the 40th percentile in 1980, 1990, and 2000.

**Number of times Gini coefficient was above the 60th percentile in 1980, 1990, and 1999.

\section{Statistical analysis}

Linear and logistic regressions were used to evaluate the relationship of the measures of socioeconomic position and health behaviours with BMI and overweight, respectively. To evaluate the association of cumulative area-based adverse socioeconomic indices with BMI and overweight, we used multilevel models to take into account the hierarchical nature of the data (subjects clustered within provinces). We estimated random-effect models with a random intercept for each province. Multilevel linear regression and multilevel logistic regression were used to evaluate the association of each index with BMI and overweight, respectively. ${ }^{19-21}$

Provincial fixed parameters were expressed as differences with $95 \%$ confidence intervals (CI) for BMI, and as odds ratios (OR) with $95 \%$ CI for overweight. We also calculated provincial and individual-level variances and intraclass correlation (percentage of the total variance in the outcome that is attributable to the province). In the case of overweight we calculated the median $\mathrm{OR}$, whereas the intraclass correlation was approximated according to the latent variable method. ${ }^{22} 23$ To determine the proportion of differences between provinces in BMI and the prevalence of overweight that is explained by the different variables, we calculated the proportional change in variance. ${ }^{24}$
Finally, a multilevel logistic regression model was used to examine whether the availability of sports facilities was responsible for area differences in physical inactivity, one of the main risk factors for high BMI and overweight.

\section{RESULTS}

Table 1 shows characteristics of the study subjects and the mean number of sports facilities, according to each of the three indices of cumulative area-based adverse socioeconomic environment. Table 2 shows the association of age, sex, measures of socioeconomic position, and health behaviours with BMI and overweight based on a multivariate model. All these factors were independently associated with BMI and/or overweight. A sensitivity analysis was performed on the variable income, introducing quartiles of household income in the models instead of equivalent household income, but little change was seen in the results.

Tables 3 and 4 show the association of cumulative area-based adverse socioeconomic environment with BMI and overweight. There was a significant graded association of the indices based on the percentage of the population with low educational achievement and on GDPpc with BMI and overweight. We 
Table 4 Odds ratio $(95 \% \mathrm{Cl})$ in overweight according to cumulative area-based adverse socioeconomic environment indices, province-level variance, median odds ratio and intraclass correlation

\begin{tabular}{|c|c|c|c|c|}
\hline Index of socioeconomic environment & Adjusted for age and sex & $\begin{array}{l}\text { Adjusted for age, sex, } \\
\text { and measures of SEP } \dagger\end{array}$ & $\begin{array}{l}\text { Adjusted for age, sex, } \\
\text { measures of SEP, and } \\
\text { health behaviours }\end{array}$ & $\begin{array}{l}\text { Adjusted for age, sex, } \\
\text { measures of SEP, health } \\
\text { behaviours } \S \text {, and sport } \\
\text { facilities }\end{array}$ \\
\hline \multicolumn{5}{|c|}{ No of times \% population with low educational achievement was high } \\
\hline 0 & 1.00 & 1.00 & 1.00 & 1.00 \\
\hline $1-2$ & $1.37(1.13$ to 1.65$)$ & $1.29(1.08$ to 1.53$)$ & $1.28(1.08$ to 1.53$)$ & $1.30(1.11$ to 1.52$)$ \\
\hline 3 & $1.61(1.59$ to 1.64$)$ & $1.50(1.32$ to 1.71$)$ & $1.49(1.30$ to 1.70$)$ & $1.46(1.29$ to 1.65$)$ \\
\hline $\mathrm{p}$ Value for trend & $<0.001$ & $<0.001$ & $<0.001$ & $<0.001$ \\
\hline Province-level variance $(\mathrm{SE})^{*}$ & $0.030(0.011)$ & $0.022(0.009)$ & $0.023(0.009)$ & $0.0132(0.007)$ \\
\hline Median OR & 1.18 & 1.15 & 1.16 & 1.12 \\
\hline ICC (latent variable method) & $0.9 \%$ & $0.6 \%$ & $0.7 \%$ & $0.4 \%$ \\
\hline-2 Log likelihood & 80906.9 & 81496.1 & 81454.0 & 81309.1 \\
\hline \multicolumn{5}{|l|}{ No of times GDPpc was low** } \\
\hline 0 & 1.00 & 1.00 & 1.00 & 1.00 \\
\hline $1-2$ & $1.43(1.16$ to 1.76$)$ & 1.34 (1.11 to 1.62$)$ & 1.35 (1.11 to 1.63$)$ & $1.38(1.15$ to 1.66$)$ \\
\hline 3 & $1.46(1.24$ to 1.72$)$ & $1.37(1.18$ to 1.59$)$ & $1.34(1.15$ to 1.57$)$ & $1.31(1.12$ to 1.53$)$ \\
\hline$p$ Value for trend & $<0.001$ & $<0.001$ & $<0.001$ & $<0.001$ \\
\hline Province-level variance $(\mathrm{SE})^{*}$ & $0.046(0.017)$ & $0.034(0.012)$ & $0.036(0.013)$ & $0.026(0.011)$ \\
\hline Median OR & 1.23 & 1.19 & 1.20 & 1.17 \\
\hline ICC (latent variable method) & $1.3 \%$ & $1.0 \%$ & $1.0 \%$ & $0.8 \%$ \\
\hline-2 Log likelihood & 80904.9 & 81485.1 & 81441.4 & 81292.8 \\
\hline \multicolumn{5}{|l|}{ No of times Gini coefficient was high†† } \\
\hline 0 & 1.00 & 1.00 & 1.00 & 1.00 \\
\hline 1 & $1.18(0.94$ to 1.48$)$ & $1.13(0.93$ to 1.38$)$ & $1.12(0.92$ to 1.37$)$ & $1.19(0.99$ to 1.43$)$ \\
\hline 2 & $1.23(0.95$ to 1.58$)$ & $1.19(0.95$ to 1.49$)$ & $1.23(0.99$ to 1.54$)$ & $1.20(0.98$ to 1.48$)$ \\
\hline 3 & $1.19(0.90$ to 1.59$)$ & $1.15(0.89$ to 1.49$)$ & $1.16(0.90$ to 1.49$)$ & $1.10(0.86$ to 1.41$)$ \\
\hline $\mathrm{p}$ Value for trend & 0.132 & 0.145 & 0.102 & 0.206 \\
\hline Province-level variance $(\mathrm{SE})^{*}$ & $0.072(0.021)$ & $0.049(0.016)$ & $0.046(0.016)$ & $0.044(0.015)$ \\
\hline Median OR & 1.29 & 1.24 & 1.23 & 1.22 \\
\hline ICC (latent variable method) & $2.1 \%$ & $1.5 \%$ & $1.3 \%$ & $1.3 \%$ \\
\hline-2 Log likelihood & 80915.0 & 81488.6 & 81448.8 & 81298.9 \\
\hline
\end{tabular}

GDPpc, Gross domestic product per capita; ICC, intraclass correlation coefficient; OR, odds ratio; SE, standard error; SEP, socioeconomic position.

*Variance at the provincial level in a logit model.

$\uparrow$ Social class, educational level and income.

Health behaviours: type of breakfast, consumption of fruits and vegetables, smoking, drinking, and physical activity.

§Physical activity was not included.

T Number of times percentage of population with low educational achievement was above the 60th percentile in 1980, 1990 , and 2000.

**Number of times GDPpc was below the 40th percentile in 1980, 1990, and 2000.

$\uparrow+$ Number of times Gini coefficient was above the 60th percentile in 1980, 1990, and 1999.

found no significant association between the index based on the Gini coefficient and the two outcome variables.

The age and sex-adjusted difference in BMI between subjects living in provinces where a high percentage of the population had low educational achievement in 1981, 1991 and 2001 and those living in provinces with no history of adverse socioeconomic environment according to this index was 0.84 (95\% CI 0.60 to 1.07). Adjustment for age, sex and measures of individual socioeconomic position reduced the difference to 0.65 ( 0.45 to 0.85). Additional adjustment for health behaviours and sports facilities resulted in a difference of 0.63 (0.42 to 0.84 ), and 0.61 (0.40 to 0.82$)$, respectively (table 3 ). The results were similar for

Table 5 Province-level variance in BMI and the prevalence of overweight, and explained variance for subsequent models that includes individual and area variables

\begin{tabular}{|c|c|c|c|c|}
\hline & \multicolumn{2}{|l|}{ BMI } & \multicolumn{2}{|l|}{ Overweight } \\
\hline & $\begin{array}{l}\text { Province-level variance } \\
\text { (SE) }\end{array}$ & $\begin{array}{l}\text { Explained province- } \\
\text { level variance }(\%)^{*}\end{array}$ & $\begin{array}{l}\text { Province-level variance } \\
\text { (SE) }\end{array}$ & $\begin{array}{l}\text { Explained province- } \\
\text { level variance }(\%)\end{array}$ \\
\hline Model 1: age + sex & $0.247(0.065)$ & Reference & $0.081(0.022)$ & Reference \\
\hline $\begin{array}{l}\text { Model 2: model } 1+\text { individual measures of socioeconomic position } \\
+ \text { health behaviours }\end{array}$ & $0.145(0.045)$ & 41.3 & $0.056(0.017)$ & 30.9 \\
\hline Model 3: model $2+$ sports facilities & $0.131(0.041)$ & 47.0 & $0.047(0.015)$ & 42.0 \\
\hline Model 4: model $3+$ no of times $\%$ population with no education was high & $0.050(0.023)$ & 79.8 & $0.013(0.007)$ & 84.0 \\
\hline Model 5: model $3+$ no of times GDPpc was low & $0.074(0.029)$ & 70.0 & $0.026(0.011)$ & 67.9 \\
\hline Model 7: model $3+$ no of times Gini coefficient was high & $0.114(0.039)$ & 53.8 & $0.044(0.015)$ & 45.7 \\
\hline
\end{tabular}

BMI, Body mass index; GDPpc, gross domestic product per capita; SE, standard error.

*(Variance of the initial model - variance of the present model)/variance of the initial model. 
the association between the number of times GDPpc was low during the past two decades and BMI.

The odds of overweight in subjects in provinces where a high percentage of the population had low educational achievement in 1981, 1991 and 2001 were 1.61 times greater (95\% CI 1.59 to 1.64) than in individuals living in provinces with no history of this type of adverse socioeconomic environment. Adjustment for age, sex and measures of individual socioeconomic position reduced the OR to 1.50 (1.32 to 1.71). Additional adjustment for health behaviours resulted in an OR of 1.49 (1.30 to 1.70), and finally, the inclusion of sports facilities yielded an OR of 1.46 (1.29 to 1.65; table 4). The results for the association between cumulative low GDPpc and overweight were similar. The only exception was that the highest OR after adjusting for all the variables was seen in the provinces that had low GDPpc one or two times.

As can be seen in tables 3 and 4 , there was very little clustering of either BMI or overweight (intraclass correlations in the different models ranged between $0.3 \%$ and $2.1 \%$ ), suggesting much greater heterogeneity within than between provinces. Intraclass correlations and median OR were larger in the models that included the index based on the Gini coefficient, thus they explain a smaller percentage of the provincial variance. Table 5 shows that the cumulative area-based income inequality explains a smaller proportion of provincial differences in BMI or prevalence of overweight than the other two indices of cumulative area-based adverse socioeconomic environment.

There was a graded association between the number of sports facilities and the prevalence of physical inactivity. Subjects living in provinces with fewer sports facilities had an odds of physical inactivity 1.43 times higher (1.07 to 1.92$)$ than those living in provinces with a larger number of sports facilities, after adjusting for rurality, population density and measures of socioeconomic position (table 6). The association disappeared after adjusting for either the education or the gross domestic product indicator of adverse socioeconomic environment.

\section{DISCUSSION}

Our results show a graded association between the number of periods of adverse socioeconomic environment based on indicators reflecting the percentage of the population with low educational achievement or GDPpc and the outcome variables.
It has been suggested that the relationship between areabased socioeconomic environment and BMI and overweight may be the result of area differences in the prevalence of individual determinants of BMI or overweight, such as physical activity, dietary patterns, smoking and alcohol intake. ${ }^{14}$ Although health behaviours were associated with the outcome variables, adjusting for these individual determinants reduced only slightly the association of cumulative area-based adverse socioeconomic environment with BMI and overweight. Given the possibility that the measures of health behaviour are unreliable, we cannot rule out a measurement error in these individual determinants as a possible explanation for the residual association of cumulative area-based adverse socioeconomic environment with BMI and overweight.

It has also been argued that the socioeconomic environment of an area may affect BMI and overweight through potential community-level mediators, such as access to supermarkets, the price of healthy food, and community access to sports facilities and parks. $^{3-5}$ Furthermore, it has been noted that these characteristics would be responsible for individual determinants such as dietary patterns or physical activity. ${ }^{1}$ The availability of sports facilities explained part of the between-province variance. After adjusting for this variable, the association between cumulative area-based adverse socioeconomic environment and BMI or overweight decreased slightly. These findings suggest that part of the effect of socioeconomic environment on $\mathrm{BMI} /$ overweight may be mediated by the provincial supply of sports facilities and its relationship with physical inactivity. Nevertheless, the relationship between the availability of sports facilities and physical inactivity disappeared after adjusting for the measures of cumulative area-based adverse socioeconomic environment, suggesting this variable may be an indicator of exposure to socioeconomic environment rather than a factor responsible for the observed differences in physical inactivity.

We did not evaluate the possible mediating role of the price and availability of healthy food. Nevertheless, evidence of the relationship between the socioeconomic environment of the area of residence and access to "healthier" food comes mainly from the United States, whereas this kind of evidence is less consistent in other developed countries. ${ }^{25}$

Another explanation for the residual association observed could be what has been called the influence of contagion in the area of residence; ${ }^{26}$ that is, the propensity of an individual to behave in a particular way varies with the prevalence of that

Table 6 Association between availability of sports facilities and physical inactivity, odds ratio and $95 \% \mathrm{Cl}$, and province-level variance and intraclass correlation

\begin{tabular}{|c|c|c|c|c|}
\hline & $\begin{array}{l}\text { Adjusted for age, sex, } \\
\text { rurality and population } \\
\text { density (model 1) }\end{array}$ & $\begin{array}{l}\text { Adjusted for variables of } \\
\text { model } 1 \text { and measures of } \\
\text { SEP } \uparrow \text { (model 2) }\end{array}$ & $\begin{array}{l}\text { Adjusted for variables of } \\
\text { model } 2 \text { and one index of } \\
\text { area socioeconomic } \\
\text { environment: }\end{array}$ & $\begin{array}{l}\text { Adjusted for variables of } \\
\text { model } 2 \text { and other index of } \\
\text { area socioeconomic } \\
\text { environment } \S\end{array}$ \\
\hline \multicolumn{5}{|c|}{ No of sports facilities/1000 population (quartiles) } \\
\hline$>5.6$ & 1.00 & 1.00 & 1.00 & 1.00 \\
\hline $5.6-4.3$ & $1.15(0.85$ to 1.55$)$ & $1.11(0.83$ to 1.49$)$ & $0.93(0.69$ to 1.26$)$ & $0.94(0.69$ to 1.29$)$ \\
\hline$<4.3-3.2$ & 1.61 (1.19 to 2.20$)$ & 1.54 (1.14 to 2.08$)$ & $1.24(0.91$ to 1.71$)$ & $1.20(0.87$ to 1.67$)$ \\
\hline$<3.2$ & $1.55(1.15$ to 2.10$)$ & $1.43(1.07$ to 1.92$)$ & $1.07(0.77$ to 1.49$)$ & $0.99(0.70$ to 1.40$)$ \\
\hline $\mathrm{p}$ Value for trend & 0.001 & 0.005 & 0.368 & 0.784 \\
\hline Province-level variance $(\mathrm{SE})^{*}$ & $0.143(0.035)$ & $0.135(0.034)$ & $0.103(0.028)$ & $0.107(0.029)$ \\
\hline ICC (latent variable method) & $4.1 \%$ & $3.9 \%$ & $3.0 \%$ & $3.1 \%$ \\
\hline-2 Log likelihood & 82239.8 & 82889.6 & 83035.3 & 83036.2 \\
\hline
\end{tabular}

ICC, Intraclass correlation; SE, standard error; SEP, socioeconomic position.

*Variance at the provincial level in a logit model.

† Social class, educational level and income.

\$Number of times percentage of population with low educational achievement was above the 60th percentile.

$\S$ Number of times gross domestic product per capita was below the 40th percentile. 


\section{What this paper adds}

- Our results show graded associations between cumulative area-based adverse socioeconomic environment and BMI and overweight when the socioeconomic indicators are based on educational level or wealth in an area.

- This association is not explained by individual socioeconomic characteristics and health behaviours, or by the availability of sports facilities.

- Cumulative area-based adverse socioeconomic environment based on income inequality was associated with BMI and overweight, but the magnitude of the association was not statistically significant.

behaviour in the group. ${ }^{27}$ To evaluate the importance of the mediating role of contagion, some authors have proposed that the percentage of overweight in the group studied be included in the models. ${ }^{5}$ The presence of the mean outcome of the group as a regressor in the equation, however, violates the assumptions of multivariate regression models. ${ }^{28}{ }^{29}$ The pathways involved in the association between the context of the area of residence and health may well be complex and, as noted by these authors, their identification could require other methodological approaches than those traditionally used in epidemiology..$^{27-29}$

The lack of a relationship between exposure to income inequality and the outcome variables stands in contrast to the results of two US studies that showed an association of state income inequality with BMI and obesity after adjusting for measures of individual socioeconomic position. ${ }^{35}$ Another US study also found a relationship between state income inequality and abdominal obesity. ${ }^{30}$ Stressful psychosocial environment is a mechanism by which income inequality may affect obesity. ${ }^{3} 50$ Underinvestment across a wide range of public infrastructures is another proposed mechanism to explain the relationship between income inequality and health. ${ }^{31}$

Cumulative area-based income inequality in Spain may not reflect either stressful aspects of the socioeconomic environment or underinvestment in public infrastructure. Neither can it be ruled out that the association in our study is underestimated as a result of non-differential misclassification of the exposure that reflects cumulative income inequality. Whereas the estimates of the percentage of individuals with low educational achievement and of GDPpc are based on comprehensive information-population censuses and the System of National Accounts-the Gini coefficient was obtained from surveys on population samples. The variation in the relative position of each province in accordance with its Gini coefficient during the two decades studied may have been affected by imprecise estimates of the three measurements.

Finally, this relationship may be specific to the United States: international evidence on the cross-sectional relationship between income inequality and health is inconsistent, except for US studies that have frequently observed this association with respect to various health problems. ${ }^{31-34}$ Several authors have suggested that, above a certain country level of equity in income distribution, intranational differences in income inequality do not matter for health. ${ }^{35}{ }^{36}$ Subramanian and Kawachi ${ }^{35}$ have noted that the absence of an association between income distribution and health may reflect a threshold effect of income inequality on poor health. They observed that the United States has the largest inequality in income distribution of the developed countries in which the

\section{Policy implications}

Interventions to affect health behaviours or the availability of sports facilities cannot eliminate the effect of cumulative areabased adverse socioeconomic environment on BMI and overweight.

relationship between income inequality and health has been investigated.

In interpreting our results, it must be assumed that BMI and overweight are underestimated because they are based on selfreported height and weight. ${ }^{37}{ }^{38}$ These measurement errors will certainly have underestimated the association, because there is no reason to suppose that these information biases are differential with respect to the cumulative area-based socioeconomic environment. Likewise, we cannot rule out a classification bias in the measure of exposure. In a previous study, ${ }^{39}$ the effect of childhood area of residence on health outcomes was independent of the effect of adult area of residence. We obtained information on the place of residence in 2001, but not the place of residence in the two previous decades. This bias will also have contributed to an underestimate of the true association, because it is unlikely that being overweight would cause individuals to change their residence.

Finally, one must consider whether the level of data aggregation used is the most appropriate to evaluate the association of cumulative area-based adverse socioeconomic environment with BMI and overweight. We may need to study smaller areas to evaluate whether the availability of structures for health promotion near the place of residence is responsible for this association. The association also depends on the level of decision-making with regard to investment in particular kinds of public infrastructure, such as the availability of food in centrally located markets or of sports facilities. In this regard, the use of the province as the ecological variable of analysis in our study is appropriate, because political and economic decisions affecting these types of investments are made at the provincial and regional level. This approach does not support the importance of psychosocially mediated effects between prolonged exposure to income inequality and obesity ${ }^{40}$ It is, however, consistent with the neo-materialist interpretation of the effect of income inequality on health made by Lynch $\mathrm{et} \mathrm{al},{ }^{34}$ for whom income inequality is a cluster of structural conditions determined by historical, cultural and political economic processes.

\section{Competing interests: None.}

Contributions: $E$ Regidor originated and designed the study and coordinated the writing of the article. JLG-F and E Ronda contributed to the analysis of the study and to the drafting of the paper. MEC, DM and VD contributed to the interpretation of the results and to the drafting of the paper. All authors contributed to the final version of the article. E Regidor is the guarantor of the article.

\section{REFERENCES}

1. Ellaway A, Anderson A, Macintyre S. Does area of residence affect body size and area? Int J Obes 1997;21:304-8.

2. Sundquist $\mathbf{J}$, Malmström M, Johansson SE. Cardiovascular risk factors and the neighborhood environment: a multilevel analysis. Int J Epidemiol 1999;28:841-5.

3. Diez-Roux AV, Link BG, Northridge ME. A multilevel analysis of income inequality and cardiovascular disease risk factors. Soc Sci Med 2000;50:673-87.

4. Van Lenthe FJ, Mackenbach JP. Neighbourhood deprivations and overweight: the GLOBE study. Int J Obes 2005;26:234-40.

5. Robert SA, Reither EN. A multilevel analysis of race, community disadvantage, and body mass index among adults in the US. Soc Sci Med 2004;59:2421-34. 
6. Pickett KE, Kelly S, Brunner E, et al. Wider income gaps, wider waistbands? An ecological study of obesity and income inequality. J Epidemiol Community Health 2005;59:670-4.

7. Yen IH, Kaplan GA. Poverty area residence and changes in physical activity level: evidence from the Alameda County Study. Am J Public Health 1998;88:1709-12.

8. Diez-Roux AV, Nieto FJ, Caulfield L, et al. Neighborhood differences in diet: the Atherosclerosis Risk in Communities (ARIC) study. J Epidemiol Community Health 1999:53:55-63.

9. Morland K, Diez-Roux AV, Wing S. Supermarkets, other food stores, and obesity: the atherosclerosis risk in communities study. Am J Prev Med 2006;30:333-9.

10. Giles-Corti B, Donovan RJ. Socioeconomic status differences in recreational physical activity levels and real and perceived access to a supportive physical environment. Preventive Med 2002;35:601-11.

11. Giles-Corti B, Donovan RJ. The relative influence of individual, social and physical environment determinants of physical activity. Soc Sci Med 2002;54:1793-812.

12. Brunner E. Stress and biology of inequality. BMJ 1997;314:1472-6.

13. Wilkinson RG. Health inequalities: relative or absolute material standards? BMJ 1997:314:591-5

14. Calle EE, Thun MJ, Petrelli JM, et al. Body-mass index and mortality in a prospective cohort of U.S. adults. N Engl J Med 1999;341:1097-105.

15. Buhmann B, Rainwater L, Schmauss G, et al. Equivalence scales, well-being, inequality and poverty: sensitivity estimates across 10 countries using the LIS database. Rev Income Wealth 1988;34:115-42.

16. Ma Y, Bertone ER, Stanek III EJ, et al. Association between eating patterns and obesity in a free-living US adult population. Am J Epidemiol 2003;158:85-92.

17. Eurostat. General and regional statistics. Gross domestic product indicators ESA95. http://epp.eurostat.cec.eu.int (accessed 22 June 2006).

18. Instituto Valenciano de Investigaciones Económicas. Inequality indexes in Spain, its regions and provinces. http://www.ivie.es/indexb.php?idioma =EN (accessed 22 June 2006).

19. SAS Institute Inc. SAS System for windows V8. Cary, NC: SAS Institute Inc, 1999.

20. Singer JD. Using SAS PROC MIXED to fit multilevel models, hierarchical models, and individual growth models. J Educat Behav Stat 1998;24:323-55.

21. Guo G, Zhao H. Multilevel modelling for binary data. Annu Rev Sociol 2000;26:44162.

22. Merlo J, Chaix B, Ohlsson $\mathrm{H}$, et al. A brief conceptual tutorial of multilevel analysis in social epidemiology: using measures of clustering in multilevel logistic regression to investigate contextual phenomena. J Epidemiol Community Health 2006;60:290-7.

23. Merlo J, Chaix B, Yang M, et al. A brief conceptual tutorial of multilevel analysis in social epidemiology: linking the statistical concept of clustering to the idea of contextual phenomenon. J Epidemiol Community Health 2005;59:443-9.
24. Larsen K, Merlo J. Appropriate assessment of neighborhood effects on individual health: integrating random and fixed effects in multilevel logistic regression. Am J Epidemiol 2005;161:81-8.

25. Cummins S, Macintyre S. Food environments and obesity - neighbourhood or nation? Int J Epidemiol 2006;35:100-4.

26. Ross C. Walking, exercise, and smoking: does neighborhood matter? Soc Sci Med 2000;51:265-74.

27. Diez Roux AV. Estimating neigborhood heath effects: the challenges of causal inferences in a complex world. Soc Sci Med 2004;58:1953-60.

28. Michael Oakes J. The (mis)estimation of neighbourhood effects: causal inference for a practicable social epidemiology. Soc Sci Med 2004;58:1929-52.

29. Koopman JS, Longini IM. The ecological effects of individual exposures and nonlinear disease dynamics in populations. Am J Public Health 1994;84:836-42.

30. Kahn HS, Tatham LM, Pamukk EP, et al. Are geographic regions with high income inequality associated with risk of abdominal weight gain? Soc Sci Med 1998;47:1-6.

31. Lynch JW, Davey Smith G, Kaplan GA, et al. Income inequality and mortality: importance to health of inequality income, psychosocial environment, or material conditions. BMJ 2000;320:1200-4.

32. Lynch J, Smith GD, Hillemeier M, et al. Income inequality, the psychosocial environment, and health: comparisons of wealthy nations. Lancet 2001;358:194200.

33. Mackenbach JP. Income inequality and population health. BMJ 2002;324:1-2.

34. Lynch J, Smith GD, Harper S, et al. Is income inequality a determinant of population health? Part 1. A systematic review. Milbank 0 2004;82:5-99.

35. Subramanian SV, Kawachi I. Income inequality and health: what have we learned so far? Epidemiol Rev 2004;26:78-91.

36. Islam MK, Merlo J, Kawachi I, et al. Social capital and health: does egalitarianism matter? A literature review. Int J Equity Health 2006;5:3.

37. Niedhammer I, Bugel I, Bonenfant S, et al. Validity of self-reported weight and height in the French Gazel cohort. Int J Obes Relat Metab Disord 2000;24:1111-18.

38. Nyholm M, Gullberg B, Merlo J, et al. The validity of obesity based on self-reported weight and height: Implications for population studies. Obesity (Silver Spring) 2007; 15:197-208.

39. Curtis $\mathbf{S}$, Southall $H$, Congdon $P$, et al. Area effects on health variation over the lifecourse: analysis of the longitudinal study sample in England using new data on area of residence in childhood. Soc Sci Med 2004;58:57-74.

40. Wilkinson RG, Pickett KE. Income inequality and population health: a review and explanation of the evidence. Soc Sci Med 2006;63:1768-84. 